Egyptian

Orthodontic Journal

\title{
TRANSVERSE SKELETAL AND DENTAL FEATURES OF HIGH, AVERAGE AND LOW ANGLE CASES IN THE MIXED DENTITION STAGE
}

\author{
Mohamed I. Mowafy
}

ABSTRACT:

The purpose of this study was to investigate maxillary and mandibular transverse skeletal and dental width in untreated subjects with low, average, and high mandibular plane angles. Methods: sixty untreated male and female children with low $\left(\leq 23^{\circ}, n=20\right)$, average $\left(>23^{\circ}\right.$ to $\left.<29^{\circ}, n=20\right)$, and high $\left(\geq 30^{\circ}, n=20\right)$ mandibular plane angles were selected. For each subject dental casts, lateral and posteroanterior cephalometric x-rays were taken and the widths of maxilla and mandible, the intermolar and intercanine widths were measured. Results; $\mathcal{N}$ o significant differences were found in the dental nor skeletal widths between the three tested groups neither in males nor in females.

\section{INTRODUCTION}

Beauty and harmony are the core of the Orthodontic profession and for as much debate as there is on beauty, a balanced proportionate face is considered more beautiful by almost everybody. Therefore balance between the vertical and horizontal proportions of the face is of most importance to the clinician.

It seems that there is a general consensus that narrow arches and faces always exist in a long face and vice versa which means that longer or shorter faces are always imbalanced.

Christie ${ }^{1}$ evaluated orthodontic records of 82 white adults (43 women, 39 men) with normal untreated occlusions and found that short-face men had greater maxillary and mandibular widths than normal men. However, no differences in width were found between short-face and normal women. He did not provide data on long-face subjects because the sample size was too small (only 4).

\footnotetext{
* Lecturer of orthodontics, Orthodontic department, Faculty of Dentistry, Alexandria University.
} 
Wagner and Chung ${ }^{2}$ concluded in their study -on 81 females only- that starting at age 6, the high-angle group had smaller skeletal maxillary and mandibular widths than the low-angle group. This trend was consistent until age 18 years. So they concluded that vertical facial patterns (with low or high MP-SN angles) might play a strong role in the transverse growth of the maxilla and the mandible.

As for dental arches Graber $^{3}$ said that clinical examination will reveal exceptions and gradations in the degree of narrowness or broadness of the dental arches as correlated with facial types.

Kageyama et $\mathrm{al}^{4}$ used Pretreatment lateral cephalograms and dental study casts of 73 white Brazilians divided into 3 groups according to facial type: 17 brachyfacial, 24 mesofacial, and 32 dolichofacial to evaluate dental arch forms associated with various facial types in adolescents with Class II Division 1 malocclusions by using mathematical functions to describe the arch form at clinical bracket points. .The mandibular arch forms and sizes of the 3 facial types had similar mathematical features. Mathematical features of the maxillary arch forms indicated that the dolichofacial type had a tapered arch and the brachyfacial type had a wide arch in male subjects

\section{Materials and Methods :}

The sample consisted of 31 girls and 29 boys. The subjects were selected according to the following criteria:

1- In the late mixed dentition (10-12 years of age)

2- In good health with no history of head or facial trauma, or orthodontic treatment.

3- cases were chosen with the following distribution: low $\left(\leq 23^{\circ}, \mathrm{f}=10, \mathrm{~m}=9\right)$, average $\left(>23^{\circ}\right.$ to $\left.<29^{\circ}, \mathrm{f}=10, \mathrm{~m}=10\right)$, and high $\left(\geq 30^{\circ}, \mathrm{f}=10, \mathrm{~m}=10\right)$ mandibular plane angles.

For each subject (1) Standardized lateral and posteroanterior (PA) cephalograms were taken. (2) Dental casts were poured from alginate impressions.

The lateral and posteroanterior cephalograms were traced by hand on acetate paper. Frankfurt-mandibular plane angle was used to assign the cases into the three groups for males and females.

The posteroanterior cephalogram was used to measure: Maxillary width, Mandibular width, and Nasal width. According to Snodell, Nanda, and Currier ${ }^{5}$, as follows (Fig: 1): 
1. Nasal width (bialare width): the width of the nasal cavity from the most lateral points on the nasal aperture taken parallel to the horizontal plane.

2. Maxillary width: the width of the maxilla from bilateral points on the jugal process at the intersection of the outline of the tuberosity of the maxilla and the zygomatic buttress.

3. Mandibular width (bigonial width): the width of the mandible from points at the most lateral margin of the angle of the mandible.

Maxillary and mandibular Intermolar and Intercanine widths were measured on the dental casts using a digital caliper.

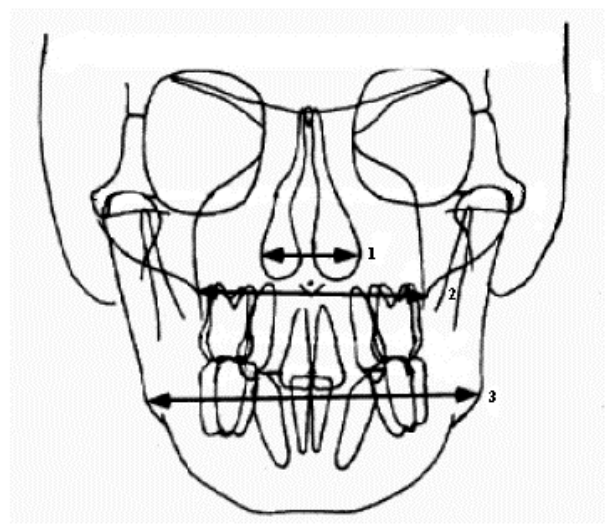

Fig. 1: Transverse measurements. 1. Nasal width (bialare width). 2. Maxillary width. 3. Mandibular width (bigonial width).

\section{RESULTS}

Table (1): Comparison between posteroanterior cephalometric measurements of the three groups in males $(\mathrm{n}=29)$

\begin{tabular}{|l|c|c|c|c|c|}
\hline \multicolumn{1}{|c|}{ Measurement } & Low & Average & High & F Test & P Value \\
\hline Bimaxillary Width & $64.48 \pm 5.26$ & $68.20 \pm 4.90$ & $63.62 \pm 4.57$ & 2.29 & $0.12 \mathrm{NS}$ \\
\hline Bigonial Width & $89.69 \pm 4.07$ & $94.09 \pm 6.05$ & $91.31 \pm 8.67$ & 1.08 & $0.35 \mathrm{NS}$ \\
\hline Nasal Width & $34.82 \pm 16.25$ & $30.29 \pm 4.62$ & $30.97 \pm 2.88$ & 0.58 & $0.57 \mathrm{NS}$ \\
\hline
\end{tabular}

Kruskal Wallis test used instead of F test

NS: Not statistically significant 
Table (2): Comparison between posteroanterior cephalometric measurements of the three groups in females $(\mathrm{n}=31)$

\begin{tabular}{|l|c|c|c|c|c|}
\hline \multicolumn{1}{|c|}{ Measurement } & Low & Average & High & F test & P value \\
\hline Bimaxillary Width & $62.93 \pm 2.72$ & $63.03 \pm 3.50$ & $64.95 \pm 3.28$ & 1.28 & $0.29 \mathrm{NS}$ \\
\hline Bigonial Width & $87.78 \pm 5.48$ & $87.90 \pm 4.61$ & $90.33 \pm 5.94$ & 0.73 & $0.49 \mathrm{NS}$ \\
\hline Nasal Width & $30.59 \pm 2.03$ & $30.00 \pm 2.44$ & $30.33 \pm 3.26$ & 0.14 & $0.87 \mathrm{NS}$ \\
\hline
\end{tabular}

Kruskal Wallis test used instead of $\mathrm{F}$ test

NS: Not statistically significant

Table (3): Comparison between dental arch measurements of the three groups in males $(n=29)$

\begin{tabular}{|c|c|c|c|c|c|}
\hline \multicolumn{1}{|c|}{ Measurement } & Low & Average & High & F Test & P Value \\
\hline Maxillary Intercanine & $34.57 \pm 3.21$ & $34.07 \pm 4.05$ & $32.80 \pm 2.64$ & 0.75 & $0.48 \mathrm{NS}$ \\
\hline Maxillary Intermolar & $51.42 \pm 3.71$ & $50.85 \pm 3.22$ & $48.50 \pm 5.08$ & 1.42 & $0.26 \mathrm{NS}$ \\
\hline Mandibular Intercanine & $28.74 \pm 3.17$ & $27.07 \pm 3.10$ & $26.49 \pm 2.11$ & 1.69 & $0.20 \mathrm{NS}$ \\
\hline Mandibular Intermolar & $45.66 \pm 3.57$ & $45.28 \pm 4.12$ & $43.37 \pm 2.92$ & 1.19 & $0.32 \mathrm{NS}$ \\
\hline
\end{tabular}

NS: Not statistically significant

Table (4): Comparison between dental arch measurements of the three groups in females $(n=31)$

\begin{tabular}{|l|c|c|c|c|c|}
\hline \multicolumn{1}{|c|}{ Measurement } & Low & Average & High & F Test & P Value \\
\hline Maxillary Intercanine & $32.71 \pm 2.15$ & $32.89 \pm 2.74$ & $32.29 \pm 2.59$ & 0.16 & $0.86 \mathrm{NS}$ \\
\hline Maxillary Intermolar & $49.01 \pm 2.74$ & $49.44 \pm 3.33$ & $48.87 \pm 3.22$ & 0.10 & $0.91 \mathrm{NS}$ \\
\hline Mandibular Intercanine & $26.95 \pm 1.78$ & $25.53 \pm 1.83$ & $26.91 \pm 1.99$ & 1.99 & $0.16 \mathrm{NS}$ \\
\hline Mandibular Intermolar & $43.32 \pm 2.36$ & $43.55 \pm 2.52$ & $41.65 \pm 3.11$ & 1.53 & $0.24 \mathrm{NS}$ \\
\hline
\end{tabular}

NS: Not statistically significant

Table (5): Comparison between posteroanterior cephalometric measurements of the three groups $(n=60)$

\begin{tabular}{|l|c|c|c|c|c|}
\hline \multicolumn{1}{|c|}{ Measurement } & Low & Average & High & F Test & P Value \\
\hline Bimaxillary Width & $63.71 \pm 4.15$ & $65.36 \pm 4.85$ & $64.28 \pm 3.93$ & 0.75 & $0.48 \mathrm{NS}$ \\
\hline Bigonial Width & $88.73 \pm 4.80$ & $90.68 \pm 6.05$ & $90.82 \pm 7.25$ & 0.73 & $0.49 \mathrm{NS}$ \\
\hline Nasal Width & $32.71 \pm 11.48$ & $30.13 \pm 3.49$ & $30.65 \pm 3.01$ & 0.73 & $0.49 \mathrm{NS}$ \\
\hline
\end{tabular}

Kruskal Wallis test used instead of F test

NS: Not statistically significant 
Egyptian

Orthodontic Journal

Table (6) Comparison between dental arch measurements of the three groups $(\mathrm{n}=60)$

\begin{tabular}{|l|c|c|c|c|c|}
\hline \multicolumn{1}{|c|}{ Measurement } & Low & Average & High & F Test & P Value \\
\hline Maxillary Intercanine & $33.64 \pm 2.83$ & $33.42 \pm 3.35$ & $32.54 \pm 2.56$ & 0.79 & $0.46 \mathrm{NS}$ \\
\hline Maxillary Intermolar & $50.22 \pm 3.41$ & $50.07 \pm 3.28$ & $48.68 \pm 4.14$ & 1.09 & $0.34 \mathrm{NS}$ \\
\hline Mandibular Intercanine & $27.84 \pm 2.67$ & $26.23 \pm 2.54$ & $26.70 \pm 2.01$ & 2.36 & $0.10 \mathrm{NS}$ \\
\hline Mandibular Intermolar & $44.49 \pm 3.18$ & $44.33 \pm 3.36$ & $42.51 \pm 3.06$ & 2.36 & $0.10 \mathrm{NS}$ \\
\hline
\end{tabular}

NS: Not statistically significant

No significant differences were found in dental or skeletal widths between the three tested groups, neither in males nor in females.

\section{DISCUSSION}

It was noticed from the literature - which is pretty scarce - that it was more assumed than proved that there was a correlation between face height on one side and facial width and arch width on the other side. It was sometimes taken as a fact that a long face has to be narrow and a short face is more inclined to be wide. So this study was designed to prove if a correlation actually exists.

Males and females were tested separately in this study because male and female subjects have different sizes in all 3 dimensions ${ }^{6,7,8,9}$ unfortunately, many previous studies, in their measurements of linear transverse dimension, combined male and female subjects. ${ }^{10,11,12}$

Actually in this study no correlation whatsoever was observed between transverse skeletal dimensions of the mandible and maxilla and the face height in males or in females. Proffit ${ }^{13}$ agrees that a patient with a large lower face height and an openbite may or may not have too long a lower face height depending on the width of the face, i.e. the proportional relationship of height and width, more than the absolute value of height, establishes the overall facial type.

Though this might seem contradictory to Ricketts ${ }^{14}$ and Graber $^{3}$ who reported that a correlation can exist between facial type and dental arch. Dolichofacial patients tend to have long, narrow faces, whereas brachyfacial patients tend to have relatively short faces and broad dental arches they didn't base their saying on actual researches.

Christie $^{1}$ agrees that there are no differences in maxillary and mandibular width between short-face and normal face height women. While short-face men

Volume 33 - June 2008 
had greater maxillary and mandibular widths than normal men but actually it was surprising that no statistics was done and his results were based on mere numerical observations.

Wagner and Chung ${ }^{2}$ results are contradictory to this study as they concluded in their study -on females only- that starting at age 6 , the high-angle group had smaller maxillary and mandibular widths than the low-angle group. This trend was consistent until age 18 years

No statistically significant difference was found between dental arch width and face height neither in males nor in females. This is a similar finding to Kagiyama $^{4}$ et al who found that the mandibular arch forms and sizes of the 3 facial types had similar mathematical features. And also females had similar maxillary arch forms in the three facial types. While a difference was only found in male subjects, the mathematical features of the maxillary arch forms indicate that the dolichofacial type has a tapered arch and the brachyfacial type has a wide arch. But it has to be taken into consideration that their study was conducted on Class II div. 1 patients only.

\section{CONCLUSION}

The following conclusions can be made from this study:

1- Maxillary and mandibular skeletal width is not related to the face height.

2- Maxillary and mandibular dental arch width is not related to the face height.

\section{REFERENCES}

1. Christie TE. Cephalometric patterns of adults with normal occlusion. Angle Orthod 1977;47:128-35.

2. Wagner DM and Chung $\mathrm{CH}$. Transverse growth of the maxilla and mandible in untreated girls with low, average, and high MP-SN angles: A longitudinal study. Am J Orthod Dentofacial Orthop 2005;128:716-23.

3. Graber TM. Orthodontics, principles and practice. 2nd ed. Philadelphia: Saunders; 1966. p. 205-7.

4. Kageyama et al. A morphological study of the relationship between arch dimensions and craniofacial structures in adolescents with Class II Division1 malocclusions and various facial types. Am J Orthod Dentofacial Orthop 2006; 129:368-75 
Egyptian

Orthodontic Journal

5. Snodell SF., Nanda RS., Currier GF. A longitudinal cephalometric study of transverse and vertical craniofacial growth. Am J Orthod Dentofacial Orthop 1993; 104:471-83.

6. Chung $\mathrm{C}-\mathrm{H}$, Wong WW. Craniofacial growth in untreated Class II subjects: a longitudinal study. Am J Orthod Dentofacial Orthop 2002;122:619-26.

7. Chung $\mathrm{C}-\mathrm{H}$, Mongiovi VD. Craniofacial growth in untreated skeletal Class I subjects with low, average, and high MP-SN angles: a longitudinal study. Am J Orthod Dentofacial Orthop 2003;124:670-8.

8. Wei SHY. Craniofacial width dimensions. Angle Orthod 1970; 40:141-7.

9. Ingerslev $\mathrm{CH}$, Solow B. Sex differences in craniofacial morphology. Acta Odont Scand 1975;33:85-94.

10. Ricketts RM, Roth RH, Chaconas SJ, Schulhof RJ, Engel GA. Orthodontic diagnosis and planning. Denver: Rocky Mountain Data Systems; 1982.

11. Ghafari J, Cater PE, Shofer FS. Effect of film-object distance on posteroanterior cephalometric measurements: suggestions for standardized cephalometric methods. Am J Orthod Dentofacial Orthop 1995;108:30-7.

12. Athanasios $\mathrm{AE}$, Droschl $\mathrm{H}$, Bosch $\mathrm{C}$. Data and patterns of transverse dentofacial structure of 6- to 15-year-old children: a posteroanterior cephalometric study. Am J Orthod Dentofacial Orthop 1992;101:465-71.

13. Proffit WR, Fields HW. Contemporary Orthodontics. 2nd ed. Mosby; p. 145.

14. Ricketts RM. Orthodontic diagnosis and planning. Vol. 1. Philadelphia: Saunders; 1982. p. 107-25. 